\title{
Mercado de Água e o Estado: Lições da Teoria dos Jogos
}

\author{
Francisco de Assis de Souza Filho \\ Universidade Federal do Ceará - UFC \\ assissouzafilho@gmail.com \\ Rubem La Laina Porto \\ Escola Politécnica - USP \\ rlporto@usp.br \\ Recebido: 26/10/07 -revisado: 25/08/08 -aceito: 09/01/09
}

\section{RESUM 0}

Este artigo analisa a relação en tre a alocação de água através de mecanismo de mercado de água mostran do a re lação que existe en tre preço de água no mercado e efetividade do sistema coercitivo estatal (identificação e punição do infrator). É demandada do Estado a garantia do usufruto dos direitos de água negociados, mesmo que isto imponha a ele os custos derivados desta ação. En tretanto mostra-se que o Estado não se desonera completamente das atividades de geren ciamento na alocação via mercado. A A ção do Estado está associada à redução dos riscos institucionais dos usuários.

Para analisar esta relação en tre Estado e M ercado foi desen volvido u m modelo matemático. 0 modelo matemático proposto é baseado: i) na teoria do crime racional no contexto da escola "Law \& Economics" para a modelagem do "roubo da água"; ii) no mercado inteligente consistin do em um centro de trocas modelado por programação linear; iii) e na teoria dos jogos para modelar a interação dos diferen tes usuários em um hidrossistema.

Os resultados do modelo mostram que, na configuração do hidrossistema analisado (Bacia do Rio Jaguaribe no Estado do Ceará), o mercado somente será eficien te se houver elevada eficiência da fiscalização para desen corajar o u suário infrator.

Palavras Chave: alocação de água, mercado de água, regulação dos recursos hídricos, fiscalização, freerider.

\section{INTRODUÇÃO}

O gerenciamento de recursos hídricos em bacias hidrográficas apresenta três fases características. A primeira é quando desenvolve-se a implantação da infra-estrutura e consiste na ampliação da oferta (gestão da oferta), em seguida a demanda cresce e preocupações com a conservação da água sem seu uso tornam-se importantes (gestão da demanda), finalmente quando os custos de nova infraestrutura para uma expansão significativa torna-se muito caro e a demanda continua a crescer tem-se a fase de alocação da água.

Esta fase de alocação é a que é vivenciada por importantes bacias hidrográficas brasileiras. Esta fase de alocação tem freqüentemente duas abordagens uma de caráter mais sociológico onde se enfoca a gestão dos conflitos sociais entre regiões, usos e usuários associados à escassez de recursos hídricos e outra de caráter econômico que tem como objetivo a alocação da água nos usos mais "eficientes". A literatura microeconômica identifica freqüentemente a alocação via mercado como a que produz a referida eficiência alocativa. Não obstante em seu "main stream" já residir à teoria de Ronald Coase que restringe a validade desta assertiva a situações em que 0 custo de transação ser zero ou baixo.

O mercado de água como uma forma de alocação que produz eficiência econômica e demanda pouca intervenção do Estado, reduzindo os custos ou desonerando-o do gerenciamento de recursos é encontrado freqüentemente na literatura de recursos hídricos. Não obstante o Banco Mundial (1993) apresentar as características especiais da água e as razões porque este mecanismo não é o usualmente escolhido pela maioria dos países.

O s critérios de seleção de um mecanismo de alocação de água devem necessariamente envolver outros aspectos além da eficiência econômica, tais como, equidade social e sustentabilidade dos ecossistemas (e de seus serviços ambientais).

Neste texto não será feita uma analise comparativa entre os diferentes mecanismos de alocação. Restringindo-se a descrição do mercado con- 
forme a literatura de recursos hídricos e propondose um modelo de simulação do mercado de água.

A metodologia da modelagem matemática dos mecanismos de mercado permite a identificação da efetividade do sistema coercitivo estatal (identificação e punição do infrator) que garanta o direito de uso da água combatendo o "roubo de água" realizado pelos "free-rider". Sem este mecanismo não haverá incentivo a trocas de mercados e o mercado será ineficiente. Este modelo cumpre desta forma a função de explicitar a relação entre Mercado e Estado, possibilitando a futura identificação dos custos que oneram o Estado nesta relação. 0 mecanismo de mercado analisado é o mercado institucionalizado através de centro de trocas com redução do custo de transação.

Este modelo baseia-se na teoria do crime racional e espande esta teoria aplicada na alocação administrativa (comando e controle) apresentada em Souza Filho e Porto (2007) e na alocação via preço Souza Filho et all(2007) para a alocação via mercado.

0 presente texto é dividido em seis partes. A primeira é esta que se encerra. A segunda apresenta a descrição do mercado na literatura de recursos hídricos. A terceira apresenta o local de aplicação da teoria. A quarta descreve a metodologia proposta a quinta descreve os resultados e os analisa e finalmente a sexta parte apresenta as conclusões.

\section{MERCADO DE ÁGUA NA LITERATURA}

Os mecanismos de mercado têm por objetivo realocar água de usos com menor capacidade de pagamento para usos com maior capacidade de pagamento por curtos períodos, em anos de escassez, ou por longo prazo. Os processos de realocação visam, freqüentemente, a transferência de água da irrigação para o uso urbano e da irrigação de menor remuneração para a de maior remuneração, sendo um mecanismo de racionamento de água.

A primeira geração de políticas ambientais é a comando e controle, a segunda geração de políticas ambientais é a cobrança e a terceira geração esta associada à idéia de trocas das permissões de lançamento e uso por mecanismos de mercado (Alcoforado, 2001).

Os mecanismos de mercado da água estão associados na economia do meio ambiente à escola da Nova Economia Institucional. Antes de se apre- sentar uma descrição do Mercado de águas apresenta-se uma breve descrição desta escola.

\section{Mercado de Água na N ova Economia Institucional}

Nova Economia Institucional (NEI). A terceira geração das políticas ambientais surge da instrumentalização de algumas idéias de Coase $(1960,1988)$. Coase realiza uma modificação na "situação quadro": A, ao produzir, danifica B.

Em todas as formulações anteriores existe uma decisão a priori de $\mathrm{A}$ indenizar $\mathrm{B}$, ancoradas no princípio do poluidor-pagador. Para aquele autor, a relação entre $A$ e $B$ é recíproca, já que, para evitar um dano em $B$, determina-se um dano em $A$, existindo, assim, uma situação circular. Um núcleo de argumentação de Coase é a determinação de quem tem o direito de danificar quem. Esta definição deve ser realizada de forma a obter a maximização do bem estar social, que pode ser fundamentada tanto na doutrina dos ilícitos civis, na regulamentação ambiental, nos mecanismos administrativos monetários ou em instrumentos econômicos.

A nova abordagem institucional tem no trabalho de Holden \& Thobani (1996) e Kemper(1997) importantes aplicações na área de recursos hídricos.

As transferências de água de um usuário para outro produzem um custo de transação. Os custos de transação estão associados a seis fatores: identificação de oportunidades, negociação da transferência, monitoramento do efeito a terceiros, transferência de águas, mitigação dos efeitos em terceiros e resolução de conflitos. Rosegrant et al. (1994). Em todos os mecanismos de alocação, o custo de monitorar o efeito em terceiros e a resolução de conflitos são custos da autoridade gestora dos recursos hídricos. A mitigação dos efeitos em terceiros deixa a autoridade para ser do usuário beneficiado pela transação, no caso de mercado de direitos. Rosegrant et al. (1994).

Em outras palavras, as barganhas que possibilitam as trocas entre os atores econômicos necessitam mobilizar recursos financeiros e tempo dos agentes a fim de serem operacionalizadas em contratos para enfim, serem executadas. 0 custo para fazer isto, em termos de tempo e finanças, são custos de transação. O s custos de transação podem ser ex-ante ( aqueles que se referem à obtenção de informações relevantes, à negociação dos acordos, ao pagamento de propina e a comunicação com as partes relevantes) e ex-post aquele que se refere à monitoração da performance dos participantes do contrato, aos cus- 
tos de sanção e governamentais e à renegociação, Kemper (1997:37).

Q uando os custos de transação são zero, segundo Coase (1960) e Coase(1988), a negociação direta de $A$ e $B$ leva naturalmente à alocação que maximiza a eficiência do sistema. Quando os custos de transação são nulos, perde-se qualquer relevância econômica ou legal o estudo da institucionalização da economia.

A análise econômica do direito parte da idéia dos custos de transação, mas analisa as condições em que o custo de transação é tão elevado que impossibilita a realocação dos direitos à propriedade e das responsabilidades, neste caso Coase entende que a especificação inicial dos direitos e responsabilidades é fundamental para a produção da eficiência econômica.

No contexto da teoria "Law \& Economics" sugere-se que, no nível mais baixo de custos de transação, o arranjo institucional recomendado é o mercado; no outro extremo, no nível mais elevado, é a regulação estatal direta, Cooter e U len (2000)

Alguns conceitos importantes da economia institucional, segundo Kemper (1997:32), são: i) racionalidade limitada (este conceito procura incorporar o efeito das informações incompletas e a incapacidade intelectual de processar toda a massa de informações); ii) arranjos institucionais (estes têm por objetivo operacionalizar os incentivos aos atores econômicos) ; iii) contratos e direitos de propriedade; iv) custos de transação; v) dependência da trajetória (as estruturas institucionais atuais e históricas condicionam as possibilidades de mudança).

Mercado de Águas em Recursos Hídricos

Os mecanismos de alocação via Mercado tem as seguintes características segundo Dinar et al. (1997):

\section{i.Visão Geral:}

- Prevê a troca de direitos da água entre os usuários (o direito de uso da água é alienável)

- Do ponto de vista econômico, um mercado competitivo tem as seguintes condições: a) vários idênticos vendedores e compradores; b) as decisões de cada comprador ou vendedor é independente dos demais; $c$ ) as decisões de um indivíduo não afetam as decisões dos de- mais; d)os indivíduos são motivados peloslucros.

- Em recursos hídricos necessita-se acrescentar: e) definição da alocação inicial da água; f)a criação de um arcabouço legal e institucional para as trocas; g) investir na infra-estrutura necessária para a transferência de água.

ii.Vantagens:

- Promove trocas entre o setor urbano e agrícola, gerando benefícios porque: a) proporciona o uso mais eficiente na agricultura, reduzindo as perdas na irrigação; ii)com o mercado de águas os fazendeiros internalizam o custo social da água.

- O mercado necessita do consentimento e possibilita a realocação de água com compensação pela transferência.

- Outro fator importante é a segurança na permissão de uso, possibilitando investimento em conservação de água.

- Proporciona grande flexibilidade nos direitos de uso

\section{iii.Desvantagens}

- Dificuldades para a implantação de um mercado de água: a) medição de água; definição de direito de uso quando o escoamento é variável; c) venda de água para obter dinheiro rápido pelos fazendeiros pobres; d) impactos sobre terceiros da transferência e degradação ambiental.

- A transferência de água da irrigação para o abastecimento urbano reduz a água de retorno, impactando terceiros.

Como já observado, os mecanismos de mercado têm por objetivo realocar água de usos com menor capacidade de pagamento para usos com maior capacidade de pagamento por curtos períodos, em anos de escassez, ou por longo prazo.

O setor urbano é o maior protagonista na necessidade de realocação de água. A forma clássica de resolver os déficits de água para os grandes centros urbanos é a importação de água de bacias que, freqüentemente, têm outros usos anteriores a esta demanda urbana. Sistemas de uso específico para a irrigação tornam-se de usos múltiplos, passando a 
promover o abastecimento dos centros urbanos, Frederiksen (1997). Este processo gera um problema de conflito intersetorial e inter-regional. A prescrição típica encontrada na literatura para este problema, como salienta Saleth et al. (2001), é a transferência intersetorial via mercado de águas. As violações potenciais de alguns pressupostos implícitos nas condições correntes minimizam a sua praticidade com solução imediata universal. Characklis et al. (1999) observa que, em condições ideais de mercado, a alta prioridade associada aos direitos municipais não é economicamente justificada.

A diferenciação da alocação de água via mercado de água e via preço do custo de oportunidade, se dá em quem obtém a renda da escassez. Rosegrant et al. (1994.). Para o referido autor, o mercado tem duas vantagens comparativas ao sistema de preço: a primeira é o menor custo da informação e a segunda é que o mercado respeita os direitos de água existentes, não podendo serem confundidos, em nenhum momento, com qualquer tipo de expropriação.

O mercado de água distingue-se de outros processos de transferência de direitos, segundo Colby (1990) porque: i) o valor da água é distinto do valor da terra; ii) o vendedor e comprador realizam a transação por acharem vantajosa para os seus interesses; iii) os termos da venda são negociados pelo comprador e vendedor, sem restrições de "ausência de lucro" ou "de custos".

Os benefícios de uma alocação via mercado de águas, segundo Rosegrant et al. (1994), são: i) a investidura de poder que se dá aos usuários que devem consentir na realocação e serão compensados por qualquer transferência de água; ii) segurança na posse dos direitos de uso da água; iii) os usuários da água consideram o custo de oportunidade total dá água; iv) a grande flexibilidade associada a este processo. U ma vantagem adicional do mercado de água para Simpson(1994) seria aliviar o governo da responsabilidade de gerenciar recursos hídricos.

Os mercados de troca de direitos de uso podem ser, segundo Holden \& Thobani (1996:6), formais (os direitos da água são independentes dos da terra e são assim tratados pelo arcabouço legal e institucional) e informais (são mercados espontâneos, e não dispõem de aparato legal e institucional e surgem devido às falhas na alocação pública de água).

O mercado de água necessita de intervenção ou controle governamental a fim de criar as condições satisfatórias para a sua ocorrência, sendo esta regulação mais difícil de ser estabelecida que a da terra, Holden \& Thobani (1996:14.) Esta intervenção contempla a definição da alocação inicial, a criação de condições legais e institucionais para a troca e o investimento em infra-estrutura que facilite as retiradas e a distribuição de água dos mananciais, Ford et al. (2001). A necessidade que o uso da água produza benefícios sociais é um requisito em mercados de água como o do Colorado (EUA).

O mercado pode ser uma solução parcial para a transferência de água às cidades. Porém, impõe questões sobre equidade e impactos nas comunidades e no meio ambiente, Burns (2003.) A mais séria limitação para o uso do mercado de água, segundo Frederiksen (1997.), é que ele falha na consecução dos objetivos nacionais, particularmente os que se referem a assuntos sociais e ambientais. Para Loehman e Dinar (1995), as incertezas naturais da água fazem a sua privatização intratável, além de diversas falhas de mercado tornarem um mercado não regulado, incapaz de produzir os resultados socialmente desejados.

A análise do mercado de direito de uso da água sob restrições ambientais pode ser encontrada em M.L. Weber (2001.) Este conclui que os mercados são úteis para alocar uma quantidade agregada de insumos ambientais, assim como para os impactos da utilização destes insumos à jusante. Quando o mercado é eficiente, as informações requeridas são muitas e que um mercado desorganizado não provê as informações necessárias aos seus participantes para uma alocação eficiente. Para que se tenha uma alocação eficiente, o mercado necessita de uma organização central que possibilite a comunicação entre os participantes do mercado: os vendedores e compradores. A falha dos mercados reais em realizar a declaração dos economistas que os mercados aumentem a eficiência e enfrentam os problemas ambientais é discutida por Carey et al. (2002). Estes autores reforçam a idéia de um local central para as trocas. Associando, em parte, as ineficiências do mercado ao custo de transação.

Para Lanna (1994), as condições econômicas necessárias para um mercado de água são: i) os consumidores e os vendedores de água, em qualquer instante, não são fazedores de preço; ii) inexistência de economia de escala no uso da água; iii) os fatores de produção devem ser móveis; iv) a água não deve ser um bem público no sentido econômico; v) não devem existir externalidades ( efeitos colaterais de uma transação em terceiros). São as seguintes condições sociais e ambientais para o referido autor: i) todas as partes atingidas pelos resultados da troca estejam envolvidas na negociação de mer- 
cado; ii) os indivíduos envolvidos na negociação de mercado estejam plenamente informados das conseqüências de suas opções; iii) não haja disparidade na distribuição de renda dos participantes do mercado.

O estabelecimento de mercados de água necessita de seis arranjos básicos para que o mercado se torne eficiente, eqüitativo e sustentável, segundo Easter et al. (1997): i) arranjos institucionais para que as trocas de água se dêem separadas das trocas de terra; ii) a criação de uma organização que gerencie a implementação das trocas, iii) infraestrutura flexível em que os vendedores e compradores possam efetivar as trocas; iv) arranjo institucional que proteja o impacto das trocas em terceiros; v) mecanismo de resolução de conflitos entre os diferentes interesses dos participantes das trocas e de terceiros; iv) mecanismo de alocação inicial de água baseado em princípios de equidade.

Os mercados de água regionais do oeste dos Estados Unidos dão evidências que sugerem que 0 preço da água é fortemente correlacionado com as especificidades do direito de água praticado e as características das transações realizadas, Colby et al. (1993). U ma análise empírica realizada pelo autor mostra que os fatores que influenciam aqueles mercados são: datas da prioridade de direito de uso, tamanho da transação, características do comprador e área geográfica na qual se dará a transação. A dispersão dos preços da água dependem para Colby et al. (1993) do próprio mercado, sendo condicionado por: formações e custo de procura, número e tamanho das trocas potenciais e heterogeneidade da commodite a ser troca.

As condições para a implementação de um mercado de água podem ser iniciadas no escopo de uma reforma para a cobrança pelo uso da aguá, Azevedo e Asad (2000:337). Análise do mercado de água nas Américas ( Estados U nidos, I lhas Canárias, Chile, Brasil e México) é apresentada por Simpson et al. (1997). Kemper et al. (1995) e Mathis (1999) apresentam a experiência de mercado de água no rio Batateiras no Estado do Ceará, Brasil. Análise comparativa entre os mercados de água do Texas e Colorado nos Estados U nidos, Austrália, Espanha e Chile é apresentada por Soares Jr. et al. (2002).

A utilização do mercado como solução paras as disputas pela água entre I srael e Palestina é proposta por Beckeret et al. (1998), modificando o padrão de uso da irrigação para outros usos. A análise de um modelo de mercado limitado no espaço é realizada por Campos et al. (2002) e Saleth et al. (1995).
Mecanismos de troca via banco de águas

O Banco de Águas é uma instituição que está pronta para comprar e vender água sob um conjunto de regras relativas a como as entidades podem participar e como os preços são estabelecidos, H owe \& Goodman (1995:124.) O banco de águas pode facilitar a compensação de terceiros através do mecanismo de preço. Howe \& Goodman (1995.)

Existem diversas experiências de bancos de água. H owe \& Goodman (1995) citam: Snake River Water Bank (1980-presente) no Estado americano de Idaho e Califórnia Drought Water Bank (1991). Todas estas experiências de banco de água tiveram aspectos positivos e negativos.

O projeto de instituições inteligentes de mercado de água, operado através de leilão de compra e venda, é proposto por Murphy et al. (2000). Nesta proposta utiliza-se experimentação em laboratório computacional para a análise dos modelos propostos.

0 mercado tem sua ocorrência condicionada por quatro características ( propriedade, alocação inicial, mecanismos de troca, regulação de trocas) que serão discutidas de forma específica, a seguir.

\section{Propriedade}

Para muitos autores o direito de propriedade é a pré-condição fundamental para a existência de mercados. Sendo esta, para Meinzen-Dick et al. (2002), a principal instituição que afeta o relacionamento das pessoas com os recursos naturais. A água é um recurso de uso comum ("common pool"). A solução da economia neoclássica para a redução da ineficiência para este tipo de bem é a privatização, Coase (1960), Coase(1988). Frohlich et al. (1995:134) argumentam que o direito de propriedade quando é outorgado define se o bem é alienável (isto é, se é negociável no meio dos indivíduos, como também se o bem é privado, de uso comum ou público). Para este autor, o fato que produz eficiência no sistema é a alienabilidade do recurso em lugar da privatização.

Os Estados U nidos têm duas doutrinas principais de direito da água a Riparian (ou doutrina dos direitos ribeirinhos) e a Prior Appropriation. A doutrina Riparian desenvolveu-se em regiões úmidas onde a água é abundante, enquanto a Prior A ppropriation, em regiões mais secas, Cech (2003:201) e Sherk (2003). As diferenças que atualmente existem entre as duas doutrinas (estados do Leste e do O es- 
te) são mais em função da cultura e da história que da geografia, Sherk (2003).

$\mathrm{Na}$ doutrina do Prior Appropriation, a prioridade temporal (o primeiro a ter direito de uso) controla a hierarquia das prioridades, o mais antigo tem prioridade maior que o mais jovem.

Os dois princípios básicos da doutrina do Riparian são o uso razoável da água e os direitos correlatos, Cech (2003:201). Nos estados do Leste americano, o conceito de prioridade temporal é utilizado, porém deverá ser balanceado pelo interesse público. Em épocas de falha no abastecimento, os estados do Leste têm como primeira prioridade o consumo humano e o saneamento; a segunda prioridade é a agricultura e a terceira prioridade são outros usos, de maneira que maximizem os empregos, e os benefícios econômicos e os objetivos do desenvolvimento sustentável, Sherk (2003). Os estados do O este estão atualmente requerendo considerações de interesse público quando a apropriação é iniciada. Em essência, os estados do Leste e 0 este estão se movendo para o princípio da "prioridade eqüitativa" que realiza um balanço de impactos entre os usuários de água existentes (prioridade temporal) com considerações de interesse público, Sherk (2003).

O sistema do Colorado tem uma característica que o distingue. Este sistema é baseado nas cortes do judi ciário, enquanto os outros sistemas do O este americano se baseiam em sistemas administrativos. Grigg (1996:343).

O sistema Prior Appropriation foi definido no Colorado, judicialmente, no julgamento pela Suprema Corte do Estado do Colorado do caso Coffin V. L eft $\mathrm{H}$ and Ditch Company (1882). Cech (2003:198)

O mercado de água do Colorado tem a água como propriedade pública e como prioridade o abastecimento humano, como estabelecem as seções 5 e 6 do artigo XVI da Constituição do Colorado, Colorado State Engineering (1999:4). Mercado ocorre sobre o direito de uso. 0 direito de água do Colorado, assim como em outros 18 estados do oeste americano, é fundado no sistema de leis dos mineiros. Em alguns estados coexistem mais de um sistema de direitos da água. Na Califórnia, por exemplo, coexistem três: 0 direito ribeirinho, herdado dos ingleses, o mercado de água e um direito herdado da época em que a Califórnia pertencia ao México. ("Puebo Rights"), MaCarthy (1995:4). A análise das potencialidades e limitações de um mercado de água na Califórnia é realizada por $\mathrm{Newlin}$ et al. (2002) que associam ao mercado de água um benefício potencial que poderia chegar, em alguns anos, a U\$1,2 bilhão/ano, com média anual de
U \$700 milhões/ ano. A análise do direito de água no Texas pode ser encontrada em Wurbs (1995).

\section{Alocação Inicial}

A alocação inicial mais freqüentemente utilizada baseia-se no uso histórico, por exemplo, Estados Unidos e Chile. Este é, provavelmente, o meIhor mecanismo do ponto de vista prático e político de alocação formal dos direitos de propriedade.

O utros critérios de alocação inicial têm sido utilizados. Um exemplo é a alocação com critérios técnicos e sociopolíticos, onde existe a necessidade de prova técnica de que o recurso hídrico está sendo utilizado para gerar benefícios sociais. 0 projeto do Colorado Big Thompson no Northern Colorado Conservancy District (NCWCD) e a Austrália (no Estado de "New Saouth Wales") são exemplos destes tipos de processo de alocação.

A alocação inicial pode ser realizada de duas maneiras: no primeiro caso, a autoridade governamental distribuiria as licenças, de forma gratuita, funcionando com o subsídio. Na segunda forma, a responsabilidade sobre a distribuição inicial recairia somente nos agentes econômicos participantes, os quais compensariam monetariamente a autoridade reguladora.

\section{M ecanismos de troca via mercado de águas}

O mecanismo de mercado baseia-se na avaliação individual do usuário do valor da água para ele. Esta avaliação se realiza com informações disponíveis para o usuário individual e são muito caras para as agências governamentais de obterem na ausência de mercados, Easter at al. (1997). Há necessidade de mecanismos de informação para que 0 mercado possa operar.

O s mercados têm no tratamento de impacto a terceiros (externalidades da troca) uma de suas maiores dificuldades. Estas externalidades podem ter impactos de segunda ordem, como, por exemplo, o desemprego causado pelo racionamento de água em uma unidade econômica e a redução a sua atividade comercial. Estes efeitos secundários no custo e no benefício são freqüentemente ignorados, pois são difíceis de serem medidos. Transferências de impactos secundários ocorrem de uma área para outra quando se dá a transferência de água. O s custos secundários nas áreas de origem são freqüentemente cobertos pelos benefícios secundários das áreas receptoras, H owe \& Goodman (1995:123). 
A necessidade de regulação das trocas

O governo é e continuará como parte inevitável das decisões de alocação de água. Sua participação, no máximo, reduzida a estabelecedor e garantidor das regras do jogo, Easter at al. (1997). A questão para estes autores é de como o governo irá promover o uso da água sem controlar, de forma direta, seu gerenciamento. Este é o primeiro e importante passo para uma alocação eficiente dos recursos hídricos.

O principal problema administrativo dos mercados de água é o impacto das trocas em terceiros devido a mudanças ocasionadas por estas nos retornos de água, na recarga dos aqüíferos e na qualidade da água, Colby (1990). 0 distrito de água no Estado do Colorado (E.U.A), Colordo Water Conservaton Board, as águas de retorno não têm cobrança ou direito de uso. O Chile e o México seguiram o modelo do Colorado, Rosegrant et al. (1994).

Os usos da água no próprio curso dágua ( $u$ sos não consultivos) e os valores de não-uso da água são questões importantes na definição de um mercado de águas, a análise da escassez é o tema-chave para analisar os tradeoffs entre usos no curso dágua (Instream) e fora do curso dágua (offstream) para Colby (1990). No Estado do Colorado (E.U.A.), o Colordo Water Conservaton Board pode apropriar água para os usos no próprio corpo dágua (nãoconsultivos) e para a manutenção do nível do reservatório.

As trocas de mercado causam externalidades na qualidade da água, existindo um tradeoff entre os ganhos nas trocas de água e um grande custo de transação associado ao controle das externalidades, como mostra Connor et al. (1999).

As dificuldades associadas ao monitoramento do uso consultivo e não-consultivo arriscam o bom funcionamento de um mercado de água. Characklis et al. (1999). Esta preocupação é presente, por exemplo, no Estado do Colorado, onde o State Engineer of Colorado (1998) apresenta um sofisticado sistema de monitoramento dos recursos hídricos utilizando satélites, estações de medição de vazões telemétricas, sistemas de apoio à decisão para integrar o conjunto dessas informações e um grande grupo de fiscais e operadores do sistema em campo.

\section{PROBLEMA E SITUAÇÃO DE APLICAÇÃO}

0 problema aqui analisado é da relação entre Estado e os agentes econômicos no mercado. Da revisão discussão apresentada no item anterior observa-se que três características podem estar contidas nesta relação: i) ação do estado de regulação e coerção ( "enforcement"); ii) a existencia de uma organização central que viabilize as trocas mitigando extrnalidades e custos de transação; iii) a garantia do pelo Estado da alienabilidade do direito de uso (não necessariamente consistindo de privatização do recurso).

Propõe-se neste artigo um modelo matemático que possibilite a analise do mercado de águas sobre diferentes sistemas de regulação e coerção. 0 mercado de água modelado é o denominado por Murphy et al(2000) de mercado inteligente que contem um centro de trocas ("trade center") sobre este mercado é aplicado a modelagem da regulação (utilizando a teoria do crime racional) apresentada em Souza Filho e Porto (2007), Souza Filho et all (2007), e Souza Filho (2005).

0 banco de águas pode agir como um centro de trocas, no entanto pode haver um centro de trocas sem que haja a formalização de um banco de águas.

Escolheu-se como exemplo de aplicação da metodologia desenvolvida o sistema da bacia do Jaguaribe no Estado do Ceará. A Bacia do Rio Jaguaribe tem $72.000 \mathrm{~km}^{2}$. O s usos da água na bacia são irrigação e abastecimento urbano.

Utilizando-se os dados fisiográficos e sócioeconômicos desta região construiu-se uma representação simplificada desta bacia. Assim, tem-se uma situação de aplicação hipotética ( simplificada) construída com dados reais.

Os usuários da bacia do Jaguaribe foram agrupados em nove (9) grandes áreas apresentados na Figura 1. Em cada uma destas áreas há um único tipo de usuário entre os apresentados na Tabela 1. Os dados econômico-financeiras apresentados nesta tabela foram obtidos do Estudo de Cobrança pelo U so da Água, SRH-Ce(2002).

Os agentes usuários têm a sua propriedade econômico-financeira descrita pela equação:

$$
\pi_{i}=\beta_{i} \quad Q_{i}-C V_{i} \quad Q_{i}-C F_{i} \quad K_{i}
$$

onde $\pi_{\mathrm{i}}$ é o benefício líquido ou lucro líquido; $\beta_{\mathrm{i}}$ é o benefício por unidade de vazão captada; $Q_{i}$ é a vazão efetivamente captada pelo agente usuário sempre menor ou igual a $\mathrm{K}_{\mathrm{i}}$ que é a capacidade instalada deste; $C V_{i}$ é o custo variável por unidade de vazão captada; $\mathrm{CF}_{i}$ é o custo fixo por unidade de vazão instalada e i é o agente usuário em foco. 
Cada usuário, neste exemplo, poderá instalar no máximo $\left(\mathrm{K}^{\max }\right)$ uma demanda de 10 $\mathrm{hm}^{3} /$ ano. A demanda máxima instalada no sistema seria de $90 \mathrm{hm}^{3} /$ ano. Chamar-se-á $\mathrm{hm}^{3} /$ ano de unidade de água (u.a).

A alocação inicial foi realizada outorgandose a cada usuário o licença de uso igual a 5 u.a.

Tabela 1 - Centros de demanda com o rendimento bruto $(R B)$, custo variado (CV) e custo fixo (CF) em Milhões

$\mathrm{R} \$$ / ( hm3/ ano)) e o valor da demanda(VD) em ( $\mathrm{hm} 3 / \mathrm{ano})$

\begin{tabular}{lllll}
\hline Produtor & VD & RB & CV & CF \\
\hline Total Perímetro DIJA & 22,10 & 0,276 & 0,209 & 0,028 \\
\hline $\begin{array}{llll}\text { Produtores de Grãos } \\
\text { em Icó }\end{array} 55,81$ & 0,150 & 0,056 & 0,081 \\
\hline
\end{tabular}

Carcinicultores Baixo

$\begin{array}{lllll}\text { Jaguaribe } & - & 1,209 & 0,689 & 0,130\end{array}$

\section{MODELO MATEMÁTICO}

De forma a exemplificar a metodologia de modelagem do mercado sobe dada situação de regulação foi desenvolvido um modelo matemático para representar uma situação institucional descrita a seguir:

I. Cada usuário tem um Licença inicial $\mathrm{L}_{0}$

II. É permitida a alienação sazonal do direito de uso, isto é, há a possibilidade dos usuários sazonalmente alugarem esta licença para um outro usuário.

III. A transação entre os usuários é realizada em centro de trocas.

IV. A operação das trocas se realizada com cada usuário revelando ao centro de trocas por qual preço $\left(P_{v} / P_{C}\right)$ ele esta disposto a vender/ comprar parte do seu direito de uso $\left(Q_{v} / Q_{c}\right)$.

V. Após confluírem as propostas ao centro de trocas é calculado neste centro o preço da água $\left(p_{s}\right)$ em cada nó da rede e o quantidade transacionado por cada usuário.

VI. Cada usuário obtém a informação das trocas realizadas e de sua licença após estas trocas $L_{i}$. E define a demanda a ser instalada $\left(K_{i}\right)$. Se $K_{i}$ for maior que a licença instada haverá retirada inlegal $\left(\alpha_{1}\right)$ uma ação caroneira (freerider) por parte do usuário. Estando o mesmo retirando água ilegalmente (crime racional).
VII. O Estado através da agência reguladora realiza a fiscalização para identificar as retiradas ilegais e pune os infratores com multa M. Esta fiscalização tem um efetividade $p$ (entendida como a probabilidade de identificar um infrator, Souza Filho (2005)).

o modelo de matemático desenvolvido simula a estratégia de cada agente usuário e a interação das mesmas no centro de trocas. De forma esquemática o modelo é apresentado na Figura 2. Descreve-se a seguir este sistema de forma mais detaIhada. Esta descrição é realizada em três partes: i) apresenta-se inicialmente a estratégia de ação dos usuários (modelo dos usuários), ii) em seguida a modelagem matemática do centro de trocas e iii) finalmente a modelagem da dinâmica do sistema usuário/ centro de trocas/ agência reguladora.

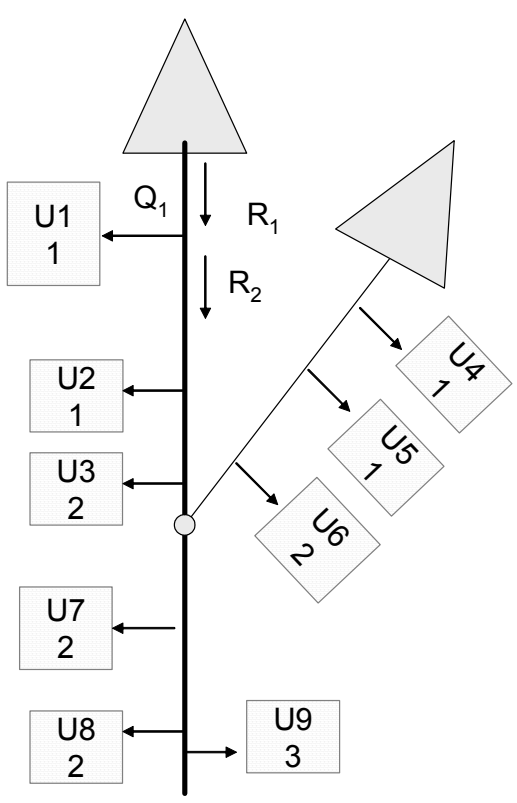

Figura 1: Disposição dos U suários na Rede Fluvial modelada

Modelo do Usuário de Água

Os usuários de água são modelados sobre uma ética utilitarista e possuem como objetivo a maximização de sua renda líquida $\left(\pi_{i}\right)$. Dois tipos de restrição são impostas ao usuário a primeira é institucional e estática e consiste no seu direito de uso inicial $\left(L_{0, i}\right)$ e a segunda é hidráulica e dinâmica e consiste na disponibilidade hídrica $\left(R_{\mid}\right)$na tomada d'água do usuário. Sobre estas restrições o usuário procurara alcançar seu objetivo a partir de três vari- 
áveis: o fator de sua disposição a comprar licença $\left(\gamma_{c, i}\right)$, fator de sua disposição a vender licença $\left(\gamma_{v, i}\right)$, e a demanda total instalada no período $\left(\mathrm{K}_{\mathrm{i}}\right)$. Podese formalizar de forma completa o modelo do usuário como se segue:

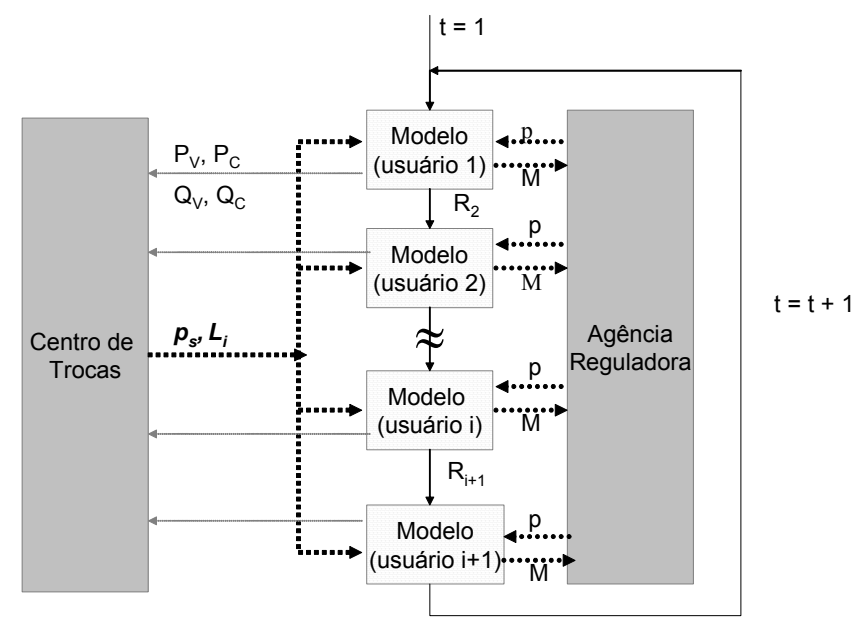

Figura 2 - Estrutura da seqüência de simulação/ otimização realizadas.

Sujeito a:

$$
\underset{K_{i}, \gamma_{\mathrm{v}, \mathrm{i}}, \gamma_{\mathrm{c}, \mathrm{i}}}{\operatorname{Max}} \pi_{i}
$$

$\begin{array}{ll}\text { Restrição na oferta: } & \mathrm{Q}_{\mathrm{i}} \leq R_{l} \\ \text { Restrição de utilização } & \mathrm{Q}_{\mathrm{i}} \leq \mathrm{K}_{\mathrm{i}} \\ \text { Restrição de Capacidade } & \mathrm{K}_{\mathrm{i}} \leq \mathrm{K}_{\mathrm{i}}^{\max }\end{array}$

onde, a renda esperada édada por:

$\pi_{i}=\beta_{i}^{\prime} \alpha 0_{i}-C F_{i} K_{i}-p T \beta_{i}^{\prime} \alpha 1_{i}+(1-p) \beta_{i}^{\prime} \alpha 1_{i}-p_{s}\left(L_{i}-L_{i, 0}\right)$

a penalidade pelo uso ilegal:

$$
\mathrm{M}_{\mathrm{i}}=\mathrm{T} \quad \beta_{i}^{\prime} \alpha_{1 \mathrm{i}}
$$

retirada legal é:

$\alpha_{0 i}=\operatorname{Min}\left(Q_{i}, L_{i}\right) ;$

A retirada ilegal:

$\alpha_{1 i}=\operatorname{Max}\left(0 ; Q_{i_{-}} L_{i}\right)$;

p é a efetividade de fiscalização ( a probabilidade de um infrator ser pego), T é o fator de penalidade, $\beta_{i}^{\prime}$ é o valor do beneficio líquido marginal $(\beta-C V)_{i}, \beta$ é o benefício, CV é o custo variável e CF é o custo fi- xo. Estes parâmetros de fiscalização são discutidos em Souza Filho (2005) e Souza Filho e Porto (2007).

O valor da disposição a comprar e a vender do usuário é definido por:

$$
\begin{aligned}
& P_{C}=\left(1-\gamma_{\text {compra }}\right)\left(1-\theta_{\text {compra }}\right)(\beta-C V)_{i} \\
& P_{V}=\left(1+\gamma_{\text {venda }}\right)\left(1+\theta_{\text {Vendara }}\right)(\beta-C V)_{i} \\
& 0 \leq \gamma_{\text {venda }} \\
& 0 \leq \gamma_{\text {compra }} \leq 1
\end{aligned}
$$

N estas expressões, Pc é o preço máximo que o usuário está disposto a pagar por uma nova licença; Pv é o preço mínimo que o usuário está disposto a vender a sua licença e ( $\beta-C V)$, é o valor do beneficio líquido marginal que o usuário teria com a utilização de uma unidade de água, sendo uma característica econômica-financeira do usuário (considerou-se fixa na estação onde se dá as trocas). 0 valor de $\gamma$ na equação acima é o fator de disposição a comprar e a vender do agente usuário e é uma função entre outros aspectos do risco que 0 agente corre devido a ineficiências da regulação (por ex. risco de não ter a quantidade, que sua licença dá direito, suprida devido à ação de um "free rider") .

Este custo de transação poderá ser diferente para compra a e a venda e admitir-se-á que ele é proporcional ao volume da transação. 0 fator de proporcionalidade entre do custo de transação será definido como custo de transação para venda ( $\theta$ venda) e custo de transação para compra (өcompra). Assumiu-se o custo de transação constante durante as trocas de um dado ano.

A quantidade que o usuário está disposto a vender pode ser expresso por:

Quantidade para vender: $\quad 0 \leq Q_{v} \leq L_{0, i}$

Q uantidade para comprar: $0 \leq \mathrm{Q}_{c} \leq \max \left(0, \mathrm{~K}-\mathrm{L}_{0, \mathrm{i}}\right)$

O usuário submete o preço e a quntidade de sua disposição a comprar e vender ao centro de trocas e após a interação com o demais usuários é calculado 0 valor das trocas em sua quantidade $\left(L_{i}-L_{0, i}\right)$ e preço $\left(p_{s}\right)$. A Figura 3 representa esquematicamente este processo na perspectiva do usuário. Isto é, a otimização do usuário incorporar dinamicamente parâmetros da interação com os demais usuários oriundas do centro de trocas e da rede hidrográfica 
(disponibilidade hídrica em função das retiradas dos demais usuários.

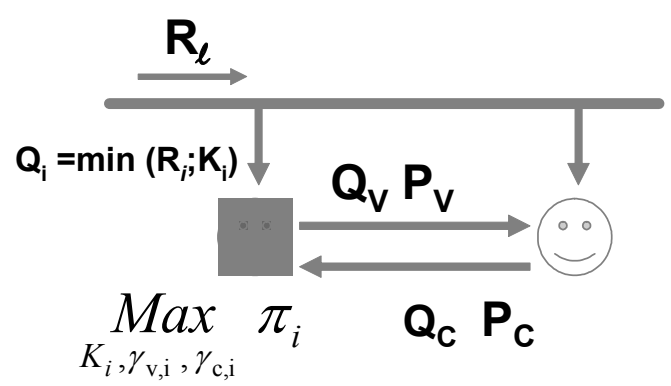

Figura 3 - Representação das trocas na perpectiva do usuário.

Centro de Trocas: Modelo do M ercado Inteligente

O mercado inteligente consiste em uma lugar onde de centralizam as trocas (Trade Center). Neste local simulam-se, computacionalmente, as trocas de forma a calcular o preço-sombra em cada um dos pontos de demanda. Este será o preço (valor econômico) da transação. 0 modelo computacional utilizado será um de otimização que utiliza programação linear por rede de fluxos. Este mercado inteligente pode operacionalizar trocas de um sistema institucional de mercado propriamente dito ou de leilões de um banco de água.

Este mercado será operado de formas que a fiscalização não é perfeita e pode haver a presença de caroneiros (free-rider). Analisa-se, neste caso, 0 impacto da fiscalização sob os preços e na produção de ineficiências econômicas no sistema de trocas.

o centro de trocas será simulado por um modelo de otimização de programação linear por rede de fluxo.

A simulação desta rede de fluxo se dará através de um algoritmo de otimização utilizando-se a técnica de programação linear por rede de fluxo. Esta otimização, terá como função-objetivo a minimização dos custos totais da rede, expressa pela equação:

$$
\begin{gathered}
\text { F.O Min } \sum_{\substack{\text { todos } \\
\text { os } \\
\text { ar cos }}} C_{i} x_{i} \\
\text { s.t }\left\{\begin{array}{l}
\sum_{\forall j \in K_{i}} x_{j}=0 \\
x_{\min , i} \leq x_{i} \leq x_{\max , i}
\end{array}\right.
\end{gathered}
$$

onde $C_{i}$ é o custo do arcos e $x_{i}$ é o valor do fluxo neste arco, j é o arco e $K_{i}$ é o conjunto dos arcos que chegam ou partem do nó i.

Nesta rede de fluxo, cada usuário é representada por um nó e por quatro arcos, como mostrado na Figura 4 e estes arcos tem seus valores máximos Tabela 2.

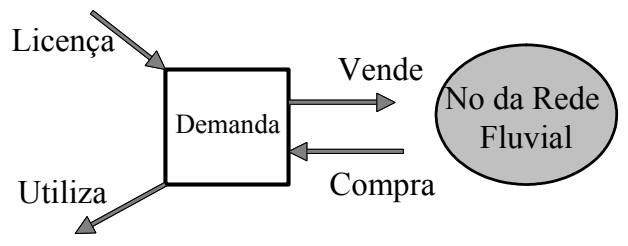

Figura 4: Arcos associados a cada nó na rede de fluxo

Tabela 2 - Valores de capacidade de transporte máxima,

\begin{tabular}{|c|c|c|c|}
\hline & Mínimo & Máximo & Custo \\
\hline Licença & $\begin{array}{c}\text { Valor da } \\
\text { Licença } \\
\left(\mathrm{L}_{\mathrm{i}, 0}\right)\end{array}$ & $\begin{array}{c}\text { Valor da } \\
\text { Licença } \\
\left(L_{i, 0}\right)\end{array}$ & Zero \\
\hline Venda & Zero & $\begin{array}{c}\text { Valor da } \\
\text { Licença } \\
\left(L_{i, 0}\right)\end{array}$ & $\begin{array}{c}\text { Mais }(+) \\
\text { Preço de } \\
\text { Venda }\left(P_{v}\right)\end{array}$ \\
\hline Compra & Zero & $\begin{array}{c}\text { MAIOR }\left(\mathrm{K}_{\mathrm{i}}-\right. \\
\mathrm{L}_{\mathrm{i}, 0} ; \text { Zero }\end{array}$ & $\begin{array}{c}\text { Menos }(-) \\
\text { Preço de } \\
\text { Compra } \\
\left(P_{C}\right)\end{array}$ \\
\hline $\begin{array}{l}\text { Utiliza- } \\
\text { ção }\end{array}$ & Zero & $\mathrm{K}_{\mathrm{i}, \max }$ & $\begin{array}{l}\text { Mais (+) } \\
\text { Custo Fixo }\end{array}$ \\
\hline
\end{tabular}
mínima e custos unitários.

A Figura 5 apresenta a rede de fluxo simulada. Nesta Figura pode-se observar que a rede de fluxo se estrutura de forma que todos os nós tem arcos que ligam ao nó de onde se originam todas as licenças ( Nó Virtual Libera Licença); e arcos que os ligam ao nó que recebe toda a água utilizada (Nó Virtual que Recebe Todas as Demandas); e por dois arcos ao nó físico da rede (Nó Rede Fluvial), um associado à venda e outro à compra de licença de direito de uso. Estes arcos têm limites máximos, mínimos de transporte e custos unitários apresentados na Tabela 2. Entendem-se custos negativos como benefícios.

0 nó que recebe as demandas tem um arco que o liga ao nó virtual que libera as demandas, co- 


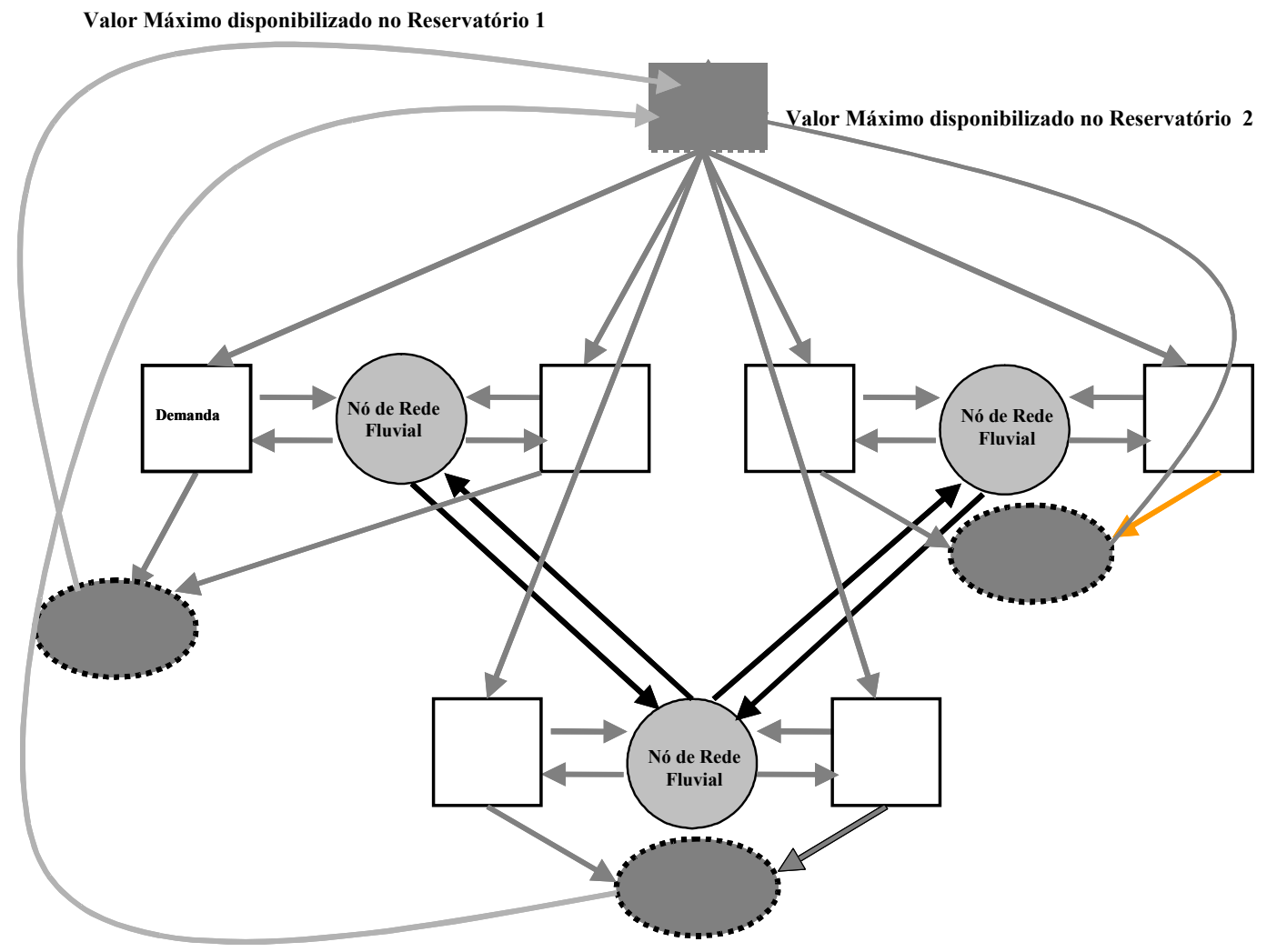

Figura 5 - Esquema simplificado da rede fluxo simulada.

bera licença) que se garante a consistência do fluxo na rede de fluxo com relação à rede hidrográfica. A capacidade máxima deste arco é igual ao total de licença que se origina no(s) reservatório(s) que podem suprir aqueles centros de demanda ligados a nó da rede fixa.

$\mathrm{Na}$ Figura 5 observa-se que o valor máximo deste arco para o nó da esquerda da figura é o total de licenças associadas ao reservatório 1; 0 da direita é o total de licenças associadas ao reservatório 2 e 0 trecho de jusante, que pode ter seu suprimento realizado pelos dois reservatórios, poderá adquirir todas as licenças disponíveis. Assim, o seu arco poderá transportar no máximo o total de licenças do sistema, isto é, o total de licenças do reservatório 1 somado ao total de licença do reservatório 2.

As Trocas de Mercado. Nesta simulação, além de ser calculado o valor transacionado e as trocas realizadas pelos diferentes usuários, será calculado o preço sombra $\left(P_{s}\right)$ da água em cada um dos nós da rede fluvial. Este preço sombra é o preço da água quando houver transação. Observa-se que 0 preço sombra não será necessariamente o mesmo em todos os nós.

\section{Dinâmica e Equilíbrio do Sistema}

Os agentes-usuários entrarão em um jogo competitivo buscando cada um maximizar o seu rendimento ( $\operatorname{Max} \pi_{\mathrm{i}}$ ) e a agência reguladora também participará deste jogo. Neste jogo o conjunto dos agentes interagirá até chegar em um Equilíbrio de Nash competitivo. O Equilíbrio Competitivo de Nash é descrito, por exemplo, Nash $(1950,1953)$, Gibbons(1992), Osborne e Rubinstein(1994) e Myerson(1997)). A descrição deste equilíbrio para uma situação de alocação comando e controle pode ser encontrada em Souza Filho e Porto (2007).

Utilizou-se para a resolução numérica dos modelos de alocação diferentes al goritmos de otimização: i) a função dos usuários foi resolvida pelo algoritimo Nelder e Mead (1965) que otimiza funções não lineares sem a utilização de gradientes; ii) e o modelo do centro de trocas utilizou a programa- 
ção linear para rede de fluxos como forma de simular as trocas em um mercado inteligente.

\section{Efetividade da Fiscalização}

0 conceito de efetividade de fiscalização ( $p$ ) foi definido em Souza Filho e Porto (2007) e Souza Filho et all e consiste na probabilidade de um usuário que retira mais água que lhe é permitido ("rouba" água) ser pego pela fiscalização. Este conceito é construído a partir da teoria do crime racional, Souza Filho et all (2007).

No caso de uma alocação administrativa (comando e controle) a efetividade de fiscalização abaixo da qual o usuário tem ação "free-rider" é $\mathrm{P}_{C R}$, definido como:

$P_{C R} \equiv \frac{1-\left(\frac{C F}{\beta-C V}\right)}{1+T}$

Onde $T$ é o fator de penalidade, $\beta$ é o benéficio, $C V$ é o custo variável e CF é o custo fixo.

Observa-se que este fator contem fatores endógenos ao usuário (benefícios e custos) e fatores do ambiente institucional (fator de penalidade e efetividade de fiscalização).

\section{ANÁLISE E RESULTADOS}

A metodologia proposta foi aplicada a Bacia do Jaguaribe de forma a simular diversos cenários de controle (fiscalização e punição). Para caracterizar os resultados obtidos foram selecionados seis cenários. Estes cenários têm fator de multa $(T)$ igual a três e efetividade da fiscalização ( $p$ ) igual a: 0,1 ; 0,$2 ; 0,3 ; 0,4 ; 0,5$ e 0,6 .

A análise destes cenários procurou identificar a relação que existe entre preço de água no mercado e efetividade da fiscalização, com vistas a identificar a importância do sistema de controle na eficiência do sistema de trocas.

A dinâmica do sistema será descrito por quatro variáveis: i) o preço de equilíbrio ou preço sombra $\left(p_{s}\right)$, ii) a licença dos usuários após a possibilidade das trocas ( $L$ ), iii) a demanda instalada (K) e iv) o parâmetros $\gamma$ de compra ( $\gamma$ compra) que descreve a disposição a comprar do usuário. A licença inicial do usuário é dada.
O comportamento destas variáveis para os diferentes usuários nos diferentes cenários simuladosé apresentado nas Figuras 6 a 9.

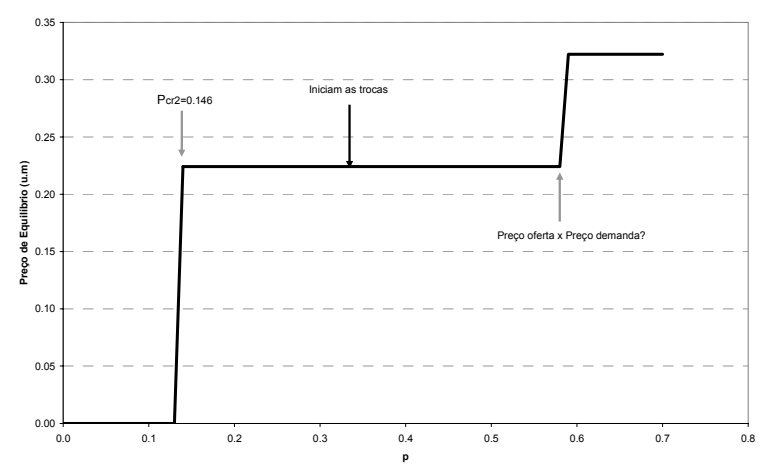

Figura 6 - Variação do preço de equilíbrio como efetividade de fiscalização.

0 preço de equilíbrio de mercado é função da efetividade de fiscalização como mostra a Figura 6. Caso a eficiência de fiscalização seja muito baixa, o preço da água no mercado é zero. A partir de um certo nível de fiscalização, o preço passa a ter valores diferentes. O s usuários só passam a ter interesse em transacionar licenças quando o a efetividade de fiscalização é superior ao $P_{C R}$ do usuário do Tipo 2 .

Este primeiro patamar observado na Figura 6 se dá quando passa a ocorrer interesse dos usuários em ter licença; o valor deste patamar se dá para 0 valor do $\mathrm{P}_{\mathrm{CR}}$ do usuário do Tipo 2. Analisando-se esta transição na Figura 8, pode-se observar que, para valores de efetividade da fiscalização $(p)$ iguais a $0,2 \& 0,3$, a licença final para todos os agentes $u$ suários é igual a 5 u.a, mesmo valor que a licença inicial indicando que não houve trocas. Assim, no trecho inicial do segundo patamar da Figura 6 há um preço de mercado para a água, porém nenhum usuário está disposto a pagá-lo. Este fato muda para eficiências de fiscalização mais elevados. Já para $p=0,4$, observa-se que três dos quatro agentes usuários do Tipo 1 vendem suas licenças para três dos quatro agentes usuários do Tipo 2. Aqui ocorre um fato interessante: Estas vendas não se deram para 0 agente usuário do Tipo 3 com maior capacidade de pagamento e este agente usuário manterá a sua licença e instalará demanda zero (Figuras 8 e 9) para todas as eficiências de fiscalização ( $p$ ) inferiores a 0,5 . Com $p$ igual a 0,5 , ele instalará sua licença inicial e continuará sem participar das trocas. Só com eficiências de fiscalização ( $p$ ) superiores a 0,6 é que este agente usuário participará do sistema de trocas. Este comportamento do agente usuário Tipo 3 é o 
fato gerador do terceiro patamar encontrado na Figura 6. Observa-se este comportamento do agente Tipo 3 encontrar-se registrado na Figura 9 quando a disposição a comprar para $\mathrm{p} \varangle 0,5$ é próximo a zero $\left(\gamma_{\text {compra }}=1\right)$.

U ma conseqüência deste comportamento é que a alocação de água para todas as eficiências de fiscalização inferiores a 0,6 é ineficiente do ponto de vistas econômico. Enfim, a alocação economicamente eficiente (disponibilizar água para os agentes econômicos que produzem mais riquezas) só se dará na configuração do sistema simulado para eficiências de fiscalização superiores a 0,6. Agrega-se a esta informação a que para $p \varangle 0,1$ o mercado agiu de forma similar a uma alocação "FreeRider", como era de se esperar.

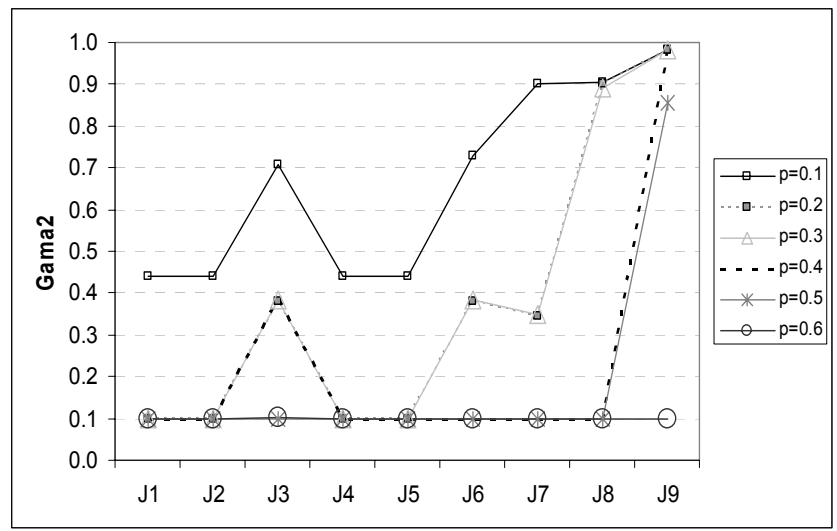

Figura 7 - valor do fator de disposição de compra ( $\left.\gamma_{\text {compra }}\right)$ no equilíbrio para cada agente usuário e diferente efetividade de fiscalização.

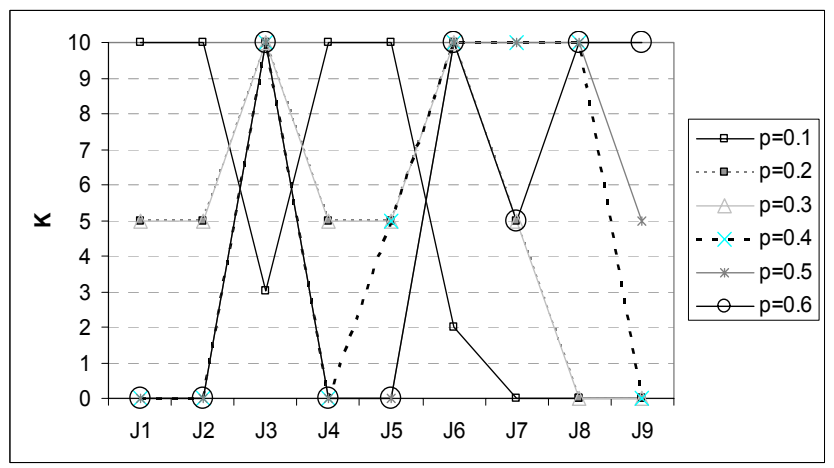

Figura 8 - Demanda instalada (K) após as potenciais trocas no equilíbrio para cada agente usuário e diferente efetividade de fiscalização.
Dois comentários adicionais são: i) estes processos de troca têm como variável de decisão dos agentes usuários a disponibilidade a comprar dos agentes usuários medida por $\gamma_{\text {comprar }}$ quanto menor este parâmetro maior a disposição a comprar do agente; ii) 0 valor de $\gamma_{\text {compra }}$ varia inversamente a eficiência de fiscalização, como pode ser observado na Figura 9.

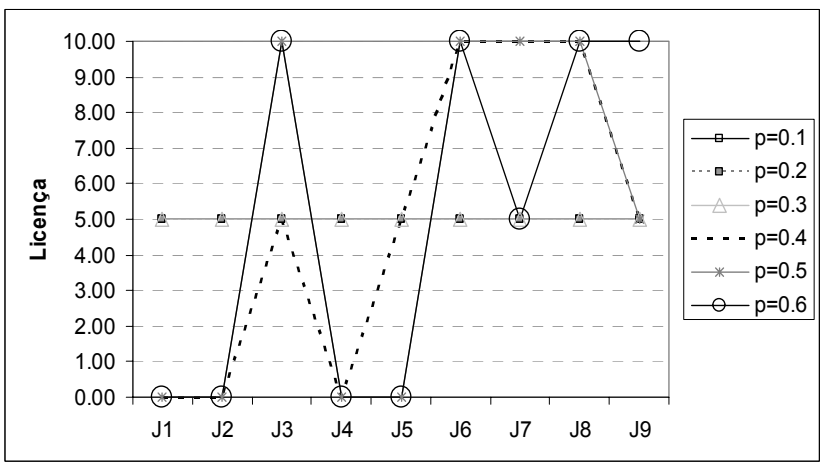

Figura 9 - Licença após as potenciais trocas no equilíbrio para cada agente usuário e diferentes ef etividade de fiscalização. A licença inicial para cada agente é igual 5 u.a.

\section{CONCLUSÕES}

Os resultados obtidos mostram a importância da ação do Estado como garantidor das trocas de mercado. Sem uma presença efetiva do Estado o mercado será ineficiente. As efetividades de fiscalização observadas nas simulações que permitem a alocação eficiente no mercado são maiores as exigidas para a garantia de direito de uso na alocação comando e controle.

A efetividade de fiscalização tem um custo associado à identificação e punição do infrator, este custo cresce com a efetividade de fiscalização. No sistema de mercado este custo é alocado para o Estado. Assim, o Estado no sistema de mercado deve no mínimo ter uma capacidade operacional que garanta os direitos de água (reduza os riscos institucionais dos usuários) e arque com os custos associados. Desta forma, na alocação de água via mercado é imprescindível à ação do Estado na garantia do usufruto dos direitos transacionados.

O s custos de transação no sistema foram incorporados no modelo de decisão do usuário. Estes custos sociais podem ser mitigados com a constru- 
ção de instituições como a do centro de trocas do mercado inteligente apresentada neste trabalho.

Existem outras dimensões da participação do Estado no mecanismo de alocação de água via mercado. Sendo estas participações tão importante como as enfatizadas na modelagem realizada como visto na revisão da literatura e impondo custos financeiros significativos ao Estado como exemplo a medição de conflitos associado a impactos a terceiros pelas transferências de uso.

O projeto de instituições de alocação de água via mercado devem considerar os parâmetros descritos neste texto com vistas a garantia da efetividade das mesmas. Assim como, outras dimensões tais como o contexto político e institucional, social e cultural.

\section{REFERÊNCIAS}

ALCOFORADO, I.G. "A Trajetória dos Fundamentos das Políticas Ambientais: do commando e controle à abordagem neo-institucionalista", IV Encontro da Sociedade Brasileira de Economia Ecologia (ECOECO), Mesa Redonda I, Belém, 2001.

AZEVEDO, L.G.T, ASAD, M. "The political process behind the implementation of bulk water pricing in Brazil". In "The political economy of water princing reform". Ed. Ariel Dinal. Oxford University, 2000a.

BRUNS, B. "Water Rights: A synthesis paper on institutional options for improving water allocation". In International Working Conference on Water Rights: institutional options for improving water allocation. Hanoi, Vietnam. February 12-15.2003.

CAMPOS, J.N.B, STUDART, T.M, COSTA, A.M. "Alocação e Realocação do Direito de Uso da Água: Uma proposta de Modelo de Mercado Limitado no Espaço". Revista Brasileira de Recursos Hídricos, AbrilJunho.Vol. 7, N.2, 2002.

CAREY, J., SUNDING, D.L., ZILBERMAN, D. "Transaction cost and trading in an immature water market". Environment and Development Economics, 7 , 733-750. 2002.

CECH, T.V. "Principles of Water Resources: history, development, management, and policy". Editora: Jonh Wiley \& Sons. 2003.

CHARACKLIS, G.W, GRIFFIN, R.C, BEDIENT, P.B. "Improving the ability of water market to efficiently manage drought". Water Resources Research. Vol. 35, N3, Março, 1999.

COASE, R.H. "The problem of social Cost". Journal of Law and Economics, N3, pp1- 44. 1960.
COASE, R.H. " The Firm, The Market, and The law". Editora Universidade de Chicago. 1988.

COLBY, B.G. "Enhancing Instream flow in a Era of Water Marketing". Water Resources Research. Vol. 26, N. 6. Junho. 1990.

COLBY, B.G., CRANDALL, K, BUSH, D. "Water Right Transaction: Market values and price dispersion". Water Resources Research. Vol. 29, N. 6. Junho. 1993.

COLORADO STATE ENGINEERING, "Synopsis of Colorado Water Law". Colorado State Engineering. Colorado, Estados Unidos, Março, 1999.

CONNOR, J.D., PERRY, G.M. "Analyzing the potencial for water quality externalities as the result of water transfers". Water Resources Research. Vol. 35. N 9. Setembro, 1999.

COOTER, R., ULEN, T. "Law \& Economics". 3 Edição. Addison Wesley Longman. 545p. 2000.

DINAR, A., ROSEGRANT, M.W, MEIZEN-DICK, R.; "Water Allocation Mechanismsprinciples and exemples". World Bank: Policy Research Working Paper \#1779, Washington, DC. 1997.

EASTER, K.W, BECKER, N., TSUR, Y. "Economic Mechanisms for managing water resources: pricing, permits and markets" ". In "Water Resources: Enviromental Planning, Management, and Development". ED. Asit K. Biwas. MCGraw-Hill company. 1997.

FORD, S., BUTCGER, G., EDMONDS, K, BRAGGINGS, A.; "Economics Efficiency of Water Allocation". Ministry of Agriculture and Florestry. Nova Zelandia. 2001.

FOX, R. L. "Optimizazation Methods for engeneering design" Ed. Addison-Wesley Publishing Company. 1971.

FREDERIKSEN, H.D. "Institutional Principles for sound managemet of water and related enviromental resources". In "Water Resources: Enviromental Planning, Management, and Development". ED. Asit K. Biwas. MCGraw-Hill company. 1997.

FROHLICH, N, Oppenheimer, J. "Alienable Privatization Polices: the choice between inefficiency and injustice" in "Water Quality/Quantity Management and Conflict Resolution: institutions, processes, and economic analyses". Editor Ariel Dinal e Edna T. Loehman. Editora Praeger. 1995.

GIBBONS, R. "Game Theory for Apllied Economists". Princeton University Press. 1992.

GRIGG, N.S; "Water Resources Management: principles, regulations, and cases". Editora: McGraw-Hill Companies.1996.

HOLDEN, P., THOBANI, M. "Tradable Water Rights: A property Rights Approach to Resolving Water Shortages and promoting investiment". Policy Research Working Paper 1627. World Bank. 1996.

HOWE, C.W., GOODMAN, D.J. "Resolving Water Trasnfer Conflits Through Changes in the Water market Proc- 
ess". In "Water Quantity/Quality management and conflict resolution". Editores: Dinal. A., Loehman, E.T., Editora Praeger Publishers. 1995.

KEMPER, K.E., GONÇALVES, J.Y.B, BEZERRA, F.W.B. "Um sistema de gerenciamento e alocação de água - 0 caso da fonte Batateira no Cariri -Ceará, Brasil". Associação Brasileira de Recursos Hídricos, XI Simpósio Brasileiro de Recursos Hídricos, Recife, Pernambuco, Brasil, 1995.

KEMPER, K.E. "O custo da água Gratuita: Alocação e Uso dos Recursos Hídricos no Vale do Curu, Ceará, Nordeste Brasileiro". Linköping Studies in Art and Science, N.152. 256 pag. 1997.

LANNA, A E, "Cobrança e Mercado de água como instrumento de gerenciamento dos recursos hídricos no semiárido do nordeste do Brasil". II Simpósio de Recursos Hídricos do Nordeste, Fortaleza, Ceará, Brasil, 1994a.

LOEHMAN, E.T., DINAL. A. "Introduction". In "Water Quantity/Quality management and conflict resolution". Editores: Dinal. A., Loehman, E.T., Editora Praeger Publishers. 1995.

MACARTHY, E. "Layperson's Guide to Water Rights Law". Water Education Fundation, California, EUA, 1995.

MATHIS, M.L. "Policy desing in a imperfect world: Essays on the management and use of open Acess renewable natural resources". Tese de Doutorado, Universidade do Texas, Agosto, 1999.

MEINZEN-DICK, R. S., PRADHAN, R. "Legal Pluralism and Dynamic Property Rights". Capri Working paper no 22, Janeiro 2002.

MURPHY, J.J, DINAR, A., HOWITT, R.E, RESSENTI, S.J, SMITH, V.L. "The Design of 'Smart' water market institutionans using Laboratory experiments". Environmental and Resources Economics 17(4), Dezembro, 2000.

NELDER, J. A. ; MEAD, R. Computer Journal. Vol. 7 p. 308313, 1965.

NEWLIN, B.D. , JENKINS, M.W., LUND, J.R. HOWITT, R.E. "Southern California Water Markets: Potencial and Limitations". Journal of Water Resources Planning and Management. Janeiro-Fevereiro, 2002.

OSBORNE, M.J, RUBINSTEIN, A. " A Course in Game Theory". MIT Press. 1994.

MYERSON, R.B. "Game Theory: Analysis of Confl ict". Havard University Press. 1997.

NASH, J. "Equilibrium Points in n-Person Games". Procedering of the National Academy os Sciences". 36:48-49. 1950.

NASH, J. "Two-Person Cooperative Games". Econometrica, 21:128-140. 1953.

RIBEIRO, M.M.R, LANNA, A.E.L. "A outorga Integrada das vazões e Captações e Diluição". Revista Brasileira de Recursos Hídricos. Vol. 8 N. 3. Julho-Setembro. 2003.

ROSEGRANT, M.W, BINSWANGER, H.P. "Markets in tradable water rights: potencial for efficiency in developing country water resoucea llocation". World Development, Vol. 22, N.11, 1994.

SRH-Ce, "Estudos para a defi nição e implementação da política tarifária de água bruta no estado do ceará: $5^{\circ}$ relatório -análise da capacidade de pagamento dosusuários de água bruta na bacia do jaguaribe parte a (irrigantes, carcinicultores e piscicultores)", Secretaria de Recursos Hídricos do Estado do Ceará. 2002.

SALETH, R.M., BRADEN, J.B. "Minimizing potencial distortion in a spot water market: a multilateral bargaining approach". In "Water Quantity/Quality management and conflict resolution". Editores: Dinal. A., Loehman, E.T., Editora Praeger Publishers. 1995.

SALETH, R.M, DINAR, A. "Preconditions for market solution to urban water scarcity: empirical results from Hyderabad City, India". Water resources Research, Vol. 37, N 1, Janeiro, 2001.

SIMPSON, L. , RINGSKOG, K. "Water Markets in the Americas". Directions in Development. World Bank, Dezembro, 1997.

SIMPSON, L.D. "Are 'Water Market' a viable option?". Finance and Development, N.31. Junho, 1994.

SHERK, G.W. "East Meets West: A tale of two water doutrines". Water Resources Impact. V.5 N.2. Março. 2003.

SOARES JR., P.R., CORDEIRO NETTO, O.M., NOQUEIRA, J.M. "As Licenças Comercializáveis e o mercado de águas. Fundamentação teórica e estudos de caso." XV Simpósio Brasileiro de Recursos Hídicos, Curitiba, Paraná, Brasil. 2002.

SOUZA FILHO, F.A. E PORTO, R. "Aocação administrativa de água: usuário free-rider e agência auto-interessada". Jornal da Associação Brasileira de Recursos Hídricos. (Submetido). 2007.

SOUZA FILHO, F.A, LALL, U, PORTO, R. "The role of price and enforcement in water allocation: insights from Game Theory in a Brazilian context". Water Resource Research (Submetido). 2007.

SOUZA FILHO, F.A. "ALOCAÇÃO DE ÁGUA SAZONAL E ANUAL: Modelos Matemáticos, Experimentação Comportamental e Justiça Alocativa. Tese de Doutorado. EPUSP. 2005.

WEBER, M.L. "Markets for water right under Enviromental constraints". Journal of Enviromental Economics and Management, 42, 53-64, 2001.

WORLD BANK; "Water Resources Management, a World Bank policy paper". World Bank, Washington, DC. 1993. 
WURBS, R.A. "Water Rights in Texas". Journal of Water Resources Planning and Management, Novembro e Dezembro, 1995.

The Water M arket and the State: Lessons From the Games Theory

\section{ABST RACT}

The paper analyses the water allocation process among users by means of market mechanisms and shows the existing relationship between water price and the effectiveness of the command and control process via permit systems. It is the responsibility of the State responsibility to guarantee water rights, even though the expen ditures associated with this process are acknowledged.. Even if the market system is used to decide the allocation process, the State will still bear the costs of enforcement. The presence and the action of the State are associated with the reduction of risk for the users.

In order to analyze this relationship between the State and the Market, a mathematical model is proposed. The mathematical model is based on: i) the rational crime the ory, in the context of the "Law \& Economics School" for water stealing actions; ii) the intelligent market, simulated as an exchange center using linear programming; and iii) the games theory to model the interaction of different water u sers in a water system.

The case study presented here shows that the market system will only be efficient if an efficient enforcement system is put in place by the State in order to inhibit the noncompliance of the water users.

Key Words: Water Allocation; Water Right; Inspection and freerider. 